\title{
CINCO MINUTOS DE SILÊNCIO
}

\author{
Raul Antelo \\ (UFSC - CNPq)
}

\begin{abstract}
Alois Riegl ha notado en el arte románico tardío una modificación decisiva en la conformación del espacio a partir de ese momento, a la que caracteriza como "emancipación del intervalo". Esto es al mismo tiempo la fórmula de la filología. Emancipa el intervalo de los fenómenos límites y, dando un paso más, descubre fenómenos a partir del intervalo entre ellos, movimientos fenomenales a partir de los afenomenales en su espacio intermedio, el espacio a partir de una cuarta dimensión, toda dimensión en última instancia a partir de lo no-dimensional.

Werner Hamacher - "Tesis 41" in 95 tesis sobre la Filología
\end{abstract}

A estrofe do Martin Fierro está para a oitava real como a redondilha para o alexandrino. A desafiadora assertiva de teoria poética foi formulada por Eugenio D’Ors, em um ensaio intitulado “Martín Fierro", incluído em Cinco minutos de silencio (1925, p.83-9). Mais tarde o texto ainda figuraria como prefácio ("Para leer el "Martín Fierro"), numa edição de luxo feita em Paris (HERNÁNDEZ, 1928, p.7-14)르 e, a seguir, dois poetas da vanguarda argentina, Francisco Luis Bernárdez e Leopoldo Marechal, mais uma vez o reproduziriam, no inverno de 1929, no único número da revista Libra.

\footnotetext{
${ }^{1}$ Prefácio de Eugenio D’Ors, ilustrado com gravuras em cobre de Héctor Basaldúa.
} 
A inclusão do texto de D’Ors na edição para bibliófilos é particularmente interessante porque ele ressoa em constelação com outros textos não menos sintomáticos: os Trois Mythes de Jules Supervielle, O cemitério marinho de Paul Valéry, traduzido por um especialista em Góngora, o poeta espanhol Jorge Guillén, e ilustrado com desenhos de Gino Severini, gravados na madeira por Pierre Dubreuil; Ollantay. Drama kechua, em tradução ao espanhol de Miguel A. Mossi e ao francês do peruano Gabino Pacheco Zegarra, defensor, à diferença de Ricardo Palma, da tese incaista da peça, precedidas ambas as traduções por um prólogo de Ventura García Calderón, e ilustradas com gravuras coloridas por um discípulo de Maillol e Bourdelle, o argentino Pablo Curatella Manes². Mas a assertiva de D’Ors, longe de acidental ou fortuita, tem conseqüências teóricas profundas. Se, de fato, a sextilha funciona para a oitava real como a redondilha para o alexandrino, isso significa que a estrofe da gauchesca é uma profanação do ritmo épico e aristocrático que coincide com o ritmo (o tempo) da colonização. Em suma, a sextilha seria a primeira libertação rítmica da linguagem poética latino-americana.

Canta el pueblero... y es pueta;

50 canta el gaucho... y jay Jesús!,

lo miran como avestruz,

su inorancia los asombra;

mas siempre sirven las sombras

para distinguir la luz.

Mas examinemos mais de perto o texto de Eugenio D'Ors, que nos oferece uma leitura do poema tão enxuta e poliédrica quanto um volume de Curatella:

Poemas exclusivo, secamente de acción - de marcha rápida y tema agrio -; poema sin perspectiva, sin paisaje ni nobleza, ha podido encontrar, en su característica estrofa, en su endiablada estrofa de seis versos, con el primero mudo, que clava en el corazón un pinchazo inquieto; con el cuarto, insolente, que introduce un nuevo consonante; con el sexto que cierra la puerta de manera tan descarada; ha podido encontrar, digo, en esa estrofa y en sus versitos cortos, el instrumento perfecto y cumplido. El instrumento de una poesía que no aspira a la música en nada, y de una mnémica que no invoca ninguna aristocracia de tradición. (D’ORS, 1925a, p.83-84)

2 Nascido em La Plata, em 1891, Curatella Manes frequentou André Lhote, cujo método estudou, Juan Gris, Ferdinand Léger, Albert Gleizes, Gino Severini, Henri Laurens e Brancusi. Participou da Bienal de Veneza em 1952 e da Bienal de São Paulo em 1957. Morreu em 1962. 
Mais adiante, D'Ors filia o poema ao romancero espanhol, porém, em chave diferente da proposta de Menéndez Pidal, por exemplo:

También nuestro romance, como la estrofa hernandina, es forma de sentido épico y exigua anchura. También aquél se presta dúctilmente a los exclusivismos de la acción pura. Pero una y otra forma, igualmente activas, no son precisas en la misma proporción. Una indecisión, una vaguedad constante, una melancolía, flotan siempre en el blando fluir del romance. El romance no tiene estrofa; sus límites son indefinidos. La música sorda de las asonancias sirve para hacerlo avanzar, no para detenerlo ni plasmarlo. No es todavía el romance un organismo poético contemplativo; pero es ya un organismo poético indolente.

La melancolía tal vez no puede ser conocida por Martín Fierro. Este héroe pasa sin tránsito de la rebeldía quejumbrosa a la cínica resignación. Siempre ácido, nunca irónico, se da a la acción sin sombra alguna de duplicidad, sin ninguna superación.

Así, cuando la posibilidad de la acción se le acaba, cesa a la vez de aventurarse y de cantar. Hasta pierde el nombre, que es algo como perder el alma.

\section{E neste ponto de perder o nome deposita D'Ors a mais funda} dimensão trágica do poema gauchesco:

Perder el nombre... ¿Puede haber mayor fracaso para el héroe? Mejor, mil veces, perder la vida. Martín Fierro pierde el nombre al final de su poema. Ulises, en un momento del suyo, también lo pierde o cambia. Pero esto, para el griego astuto, es una astucia nueva, un arma del éxito. Para el gaucho sin ventura, esto es el epílogo.

Es la ruina, en la cual su propia significación heroica se consumará. No sublimado por la victoria, sino por la ruina. Como Sigfrido, como Don Quijote - como los "perdedores", diría Gabriela Mistral - no como Ulises...

Y a la ruina corre ágilmente Martín Fierro, hombre flaco y cetrino. Corre - ligerito, ligerito, - en el fino flete de sus enjutas estrofas de seis versos (D’ORS, 1925a, p. 87).

\section{Genealogia da oitava rima}

Muitos interpretaram a ruína como autêntica arché do poema, cuja estrofe, inexistente na Argentina ou no Uruguai, proviria da tradição do Rio Grande do Sul ${ }^{3}$ e talvez, mais radicalmente, do gesto de Gonçalves

${ }^{3}$ É a tese do crítico uruguaio José Maria Fernández Saldaña (1940), renovada por Ligia Chiappini, em "Martín Fierro e a cultura gaúcha do Brasil" (2001), sem contudo contribuir com provas incontestáveis, segundo a responsável pela edição crítica para a edição Archives, a professora Èlida Lois, quem, entretanto, dá crédito à leitura da crítica holandesa Ria Lemaire, para quem a sextina, de início, uma septilha de rima aabbccb, estaria ligada ao repente cantado e à reiteração do verso inicial imposta por essa condição itinerante. 
Dias quem, querendo fazer obra nacional, recuara 300 anos na história para compor as Sextlhas de Frei Antão (1848), concebidas também como ponte entre o agora e o outrora, entre o Brasil e Portugal. Mas, para mais cabalmente avaliarmos a leitura de Eugenio D'Ors, vejamos, antes de mais nada, a genealogia da oitava rima, oitava real ou oitava heróica. Como sabemos, foi a estrofe, inspirada na tradição renascentista, em que escreveu-se, de fato, a épica ibérica. A tradição atribuiu a descoberta a Boccaccio, mas há documentos de sua existência prévia, na Sicilia, já no século XIII, com rima ABABABAB, como na métrica latina medieval. Depois de Boccaccio aclimatá-la ao italiano, Policiano, Boiardo, Ariosto e Tasso, entre tantos outros, foram alguns dos que se valeram da oitava real. Na Espanha, porém, foi Boscán quem introduziu a estrofe, no poema Octava rima; ainda quando coube, contudo, a Garcilaso de la Vega tornála mais famosa nas suas éclogas. Eis um exemplo da terceira delas:

Aquella voluntad honesta y pura,
ilustre y hermosísima María.
que en mí de celebrar tu hermosura,
tu ingenio y tu valor estar solía,
a despecho y pesar de la ventura
que por otro camino me desvía,
está y estará en mí tanto clavada,
cuanto del cuerpo el alma acompañada.

Como sabemos, Gregório de Matos usaria também essa forma, entre outras ocasiões, para louvar, não já a beleza de Maria, mas o poder do secretário de Estado da Bahia, Bernardo Vieira Ravasco, irmão do padre Antônio Vieira:

Oitavas canto agora por preceito,

Sem que na oitava possa diligente

Louvar as excelências de um sujeito,

Que pode ser em tudo o melhor Lente:

Mas como em mim não pode ser perfeito

O canto, ficará menos cadente

A música de Apolo, e de Talia,

Que não há cantar bem sem melodia.

Se do tempo perfeito o meu compasso

A compasso cantara neste canto,

Não faltara à garganta agora o passo,

E em passos de garganta fora espanto:

Porém se em canto nunca da mão passo

Como posso afinar no canto tanto, 
Que me atreva a cantar vossa ciência,

Sem que falte ao compasso na cadência?

O poeta exagera o elogio do poder até o estrambótico, um dos nomes, aliás, dado, na Sicília, à estrofe em questão ("Porém se o vosso nome o canto grave / Eleva suspendendo os mais sentidos, / Com a voz, que formar o meu alento / Chegar posso também ao Firmamento. / Discutindo esse globo de ciências / No mapa desta esfera Americana, / Acho um todo formado de excelências / Maravilha fatal em forma humana"). Assim, Gregório (1923, p. 92-96) louva, no governante, um tema banal e contingente, a passagem do seu aniversário, mesmo sabendo, não sem certa malandragem,

Que à grandeza dos orbes superiores

Ninguém pode pôr termo limitado

Diferente é o caso de Alonso de Ercilla, quem, em La Araucana (1574), traça a épica do Chile. Voltaire, que apreciou muito o poema, no qual, aliás, podemos ver alguma fonte remota para o orientalismo de Zadig e Cacambo, admirou a retórica do chefe indígena Colo Colo ao exortar os índios a não brigarem entre si e enfrentarem, no entanto, a violência colonizadora do espanhol.

\footnotetext{
Volved las armas y ánimo furioso

a los pechos de aquellos que os han puesto

en dura sujeción, con afrentoso

partido, a todo el mundo manifiesto;

lanzad de vos el yugo vergonzoso;

mostrad vuestro valor y fuerza en esto:

no derraméis la sangre del Estado

que para redimirnos ha quedado.

No me pesa de ver la lozanía

de vuestra corazón, antes me esfuerza;

más temo que esta vuestra valentía

por mal gobierno el buen camino tuerza,

que, vuelta entre nosotros la porfía,

degolléis vuestra patria con su fuerza:

cortad, pues, si ha de ser desa manera,

esta vieja garganta la primera.
}

Na poesia espanhola, a oitava rima foi empregada tanto na poesia profana quanto na religiosa, até chegarmos aos grandes poemas mitológicos, como a Fábula de Polifemo y Galatea (1613) de Góngora, 
cuja "salamandra do sol, vestido estrelas", diga-se de passagem, serviu a Augusto de Campos para uma experiência verbivocovisual. De certo modo, a oitava rima associa-se à louvação do poder, uma de cujas melhores ilustrações ainda é Os Lusíadas (1572).

\footnotetext{
As armas e os barões assinalados,

Que da ocidental praia Lusitana,

Por mares nunca de antes navegados,

Passaram ainda além da Taprobana,

Em perigos e guerras esforçados,

Mais do que prometia a força humana,

E entre gente remota edificaram

Novo Reino, que tanto sublimaram.
}

Nessa mesma linha continuariam apelando à oitava a Prosopopeia (1601) de Bento Teixeira Pinto, o Caramuru (1781) de Santa Rita Durão ou mesmo Os Escravos (1883) de Castro Alves. Contudo, dois especialistas contemporâneos, Catalina e José Palomares Espósito, em seu estudo sobre a oitava real e a épica renascentista espanhola, destacam que, na América Latina, entretanto, o metro não foi tão apreciado quanto na península.

La poesía épica hispanoamericana nos ofrece más excepciones al tradicional patrón métrico de la octava real. Melchor Xufré del Águila, natural de Madrid, capitán en la guerra de Chile -donde perdió una pierna-, es autor de un Compendio historial del descubrimiento, conquista y guerra del reino de Chile, con otros dos discursos (Lima, 1630). Esta obra está compuesta en endecasílabos sueltos. Rodrigo de Valdés, jesuita, catedrático de Prima y prefecto de estudios en el Colegio Máximo de San Pablo, es autor de un Poema heroico hispano-latino, panegírico de la fundación y grandezas de la noble y leal ciudad de Lima, publicado póstumamente por un sobrino en Madrid en 1687. Consta de unas 572 cuartetas, que mezclan voces latinas y españolas. He aquí un ejemplo de esa métrica difícil que en España representó como nadie Caramuel con su Primus Calamus. En esta línea se situaría también la Thomasiada (Guatemala, 1667), del vascongado Diego Sáenz Ovecuri, vicario provincial de San Salvador. Incluye unas ciento cincuenta maneras diferentes de versificación: cuartetas, quintillas, endechas, romances, laberintos esféricos... Y, por supuesto, distintas clases de octavas. En este sentido, ya el Licenciado Francisco López de Úbeda incluyó distintos patrones de octavas reales en la Tabla de Arte Poética que añadió a La pícara Justina (Medina del Campo, 1605). En esa Tabla incluía octavas 
de pies cortados, con hijuela y glosa, de rima a la vez interna y externa, pomposa, españolas y latinas juntamente... Por otra parte, nos referíamos al Isidro de Lope, escrito en quintillas, como su Gatomaquia. Pues bien, la quintilla -simple o doble- también va a utilizarse en Hispanoamérica. En efecto, el sevillano Luis Belmonte Bermúdez compone la Vida del Padre Maestro Ignacio de Loyola (Méjico, 1609) en quintillas dobles. Por su parte, el dominico fray Adriano de Alecio compuso una obra en loor de Santo Tomás de Aquino titulada El Angélico (Murcia, 1645), también en quintillas (ESPOSITO, 2004).

A tese do erudito Palomares Espósito reforça, assim, a posição de Eugenio D'Ors, enquanto catalão e periférico, posição que coincide, aliás, com a teoria da separação entre poesia e filosofia, exemplarmente desenvolvida por Giorgio Agamben. Em Stanze (nome, por sinal, muitas vezes atribuído à própria oitava rima), o filósofo italiano partia de um conceito de Dante, na De vulgare eloquentia, para dizer que

I poeti del '200 chiamavano «stanza», cioè «dimora capace e ricettacolo», il nucleo essenziale della loro poesia, perché esso custodiva, insieme a tutti gli elementi formali della canzone, quel joi d'amor che essi affidavano come unico oggetto alla poesia. Ma che cos'è quest'oggetto? A quale godimento la poesia dispone la sua «stanza» come «grembo» di tutta l'arte? Su che cosa si ri-chiude cosí tenacemente il suo trobar?

L'accesso a ciò che fa problema in queste domande è sbarrato dall'oblio di una scissione che si è prodotta fin dall'origine nella nostra cultura e che si suole accettare come la cosa piú naturale e che va, per cosí dire, da sé, mentre è, in realtà, l'unica cosa che meriterebbe veramente di essere interrogata. Questa scissione è quella fra poesia e filosofia, fra parola poetica e parola pensante, ed essa appartiene cosí originalmente alla nostra tradizione culturale, che già Platone poteva ai suoi tempi dichiararla «una vecchia inimicizia». Secondo una concezione che è solo implicitamente contenuta nella critica platonica della poesia, ma che ha acquistato nell'età moderna carattere egemonico, la scissione della parola è interpretata nel senso che la poesia possiede il suo oggetto senza conoscerlo e la filosofia lo conosce senza possederlo. La parola occidentale è cosí divisa fra una parola inconsapevole e come caduta dal cielo, che gode dell'oggetto della conoscenza rappresentandolo nella forma bella, e una parola che ha per sé tutta la serietà e tutta la coscienza, ma che non gode del suo oggetto perché non lo sa rappresentare.

Ciò di cui la scissione fra poesia e filosofia offre testimonianza è l'impossibilità della cultura occidentale di possedere pienamente l'oggetto della conoscenza (poiché il problema della conoscenza è un problema di possesso, e ogni problema di possesso è un problema di godimento, cioè di linguaggio). Nella nostra cultura, la conoscenza (secondo un'antinomia che Aby Warburg ebbe a diagnosticare come la « schizofrenia » dell'uomo occidentale) è scissa in un polo estatico-ispirato e in un polo razionale-cosciente, senza che nessuno dei due riesca mai a ridurre integralmente l'altro. In quanto accettano passivamente questa scissione, la filosofia ha omesso di elaborare un proprio 
linguaggio, come se potesse esistere una «via regia» alla verità che prescinda dal problema della sua rappresentazione, e la poesia non si è data né un metodo né una coscienza di sé. Ciò che, in questo modo, viene rimosso, è che ogni autentica intenzione poetica è rivolta alla conoscenza, cosí come ogni vero filosofare è sempre rivolto alla gioia. (...) La critica nasce nel momento in cui la scissione raggiunge il suo punto estremo. Essa si situa nella scollatura della parola occidentale e fa segno al di qua o al di là di essa verso uno statuto unitario del dire. Esteriormente, questa situazione della critica può essere espressa nella formula secondo la quale essa non rappresenta né conosce, ma conosce la rappresentazione. All'appropriazione senza coscienza e alla coscienza senza godimento, la critica oppone il godimento di ciò che non può essere posseduto e il possesso di ciò che non può essere goduto. In questo modo essa interpreta il precetto di Gargantua: «science sans conscience n'est que ruine de l'âme». Ciò che è recluso nella «stanza» della critica è nulla, ma questo nulla custodisce l'inappropriabilità come il suo bene piú prezioso. (AGAMBEN, 1977, p. XII-XIV)

Em várias outras oportunidades, Agamben fará referência a esse vazio central e incontornável que se instaura em muitas estruturas:

Agio è il nome proprio di questo spazio irrappresentabile. Il termine agio indica infatti, secondo il suo etimo, lo spazio accanto (adjacens, adjacentia), il luogo vuoto in cui è possibile per ciascuno muoversi liberamente, in una costellazione semantica in cui la prossimità spaziale confina col tempo opportuno (ad-agio, aver agio) e le comodità con la giusta relazione. (AGAMBEN, 2007, p. 24)

E em $O$ aberto, fazendo referência aos domínios adjacentes do homem e do animal, completa:

Rendere inoperosa la macchina che governa la nostra concezione dell'uomo significherà pertanto non già cercare nuove - più efficaci o più autentiche articolazioni, quanto esibire il vuoto centrale, lo iato che separa - nell'uomo l'uomo e l'animale, rischiarsi in questo vuoto: sospensione della sospensione, shabbat tanto dell'animale che dell'uomo. (AGAMBEN, 2002, p. 94-95)

\section{Poesia e pensamento}

Ora, essa ideia se modulará, ainda, através do hiato entre o semântico e o semiótico, que, a partir de Jakobson, foi tantas vezes formulado por Agamben. Em Ideia da prosa, lembremos, ao se referir à cesura (uma cápsula de tempo, cinco minutos de silêncio), ele associa cesura, voz e pensamento ("L'elemento, che arresta lo slancio metrico della voce, la cesura del verso è, per il poeta, il pensiero" [AGAMBEN, 1985, p. 23]), para avaliar o fenômeno com palavras de Hölderlin, poeta já invocado 
em Stanze ("Il trasporto tragico, infatti, è propriamente vuoto e il più libero. Perciò, nella successione ritmica delle rappresentazioni, in cui si espone il trasporto, diventa necessario ciò che nel metro si chiama cesura, la pura parola, l'interruzione antiritmica, per contrastare, al suo culmine, la vicenda incantevole delle rappresentazioni, in modo che venga all'apparenza non più l'alternarsi della rappresentazione, ma la rappresentazione stessa" [AGAMBEN, 1985, p. 24]). A partir dessa característica, conclui Agamben que "è questo vuoto che, come pura parola, la cesura (...) pensa, tiene in sospeso, mentre un poco si ferma il cavallo della poesia" (AGAMBEN, 1985, p. 24), imagem que ilustra, por sinal, com uma passagem de Ramon Llull, escritor medieval catalão, muito admirado por D’Ors. Poderíamos dizer, portanto, e replicando o gesto de Roberto Espósito, no prefácio à segunda edição de Categorias do impolítico, que a cápsula de silêncio não tem apenas uma avaliação simplesmente negativa ou desconstrutiva. A cesura, em resumo, serviria para que "il poeta addormentato sul suo cavallo si sveglia e contempla per un istante l'ispirazione che lo porta, non pensa nient'altro che la sua voce" (AGAMBEN, 1985, p. 24).

Mas essa cesura-esses cinco minutos que dão ao poeta a cabal contemplação da linguagem como um todo-vinculam-se, por surpreendente que pareça, à experiência de disseminação da linguagem, que se dramatizaria e encenaria, através de um funeral literário dedicado a Mallarmé4, no Jardim Botânico de Madri, em 14 de outubro de 1923, data que, para alguns, representou uma peculiar descoberta do Novo Mundo. O poeta mexicano Alfonso Reyes não só promoveu essa homenagem, como documentou a cena e estampou, na Revista de revistas (México, no 706, 2 dez.1923), uma fotografia onde aparecem seus participantes, Mauricio Bacarisse, José Bergamín, Antonio de Marichalar, José María Chacón y Calvo, Enrique Díez-Canedo, Eugenio d'Ors, José Moreno Villa e José Ortega y Gasset. Trata-se de uma cerimônia-réplica da que a Société Mallarmé, criada por Édouard Dujardin e que reunia poetas tais como Henri de Régnier, Francis Vielé-Griffin ou Paul Valéry, realizara, simultaneamente, em Valvins, evocando os 25 anos da morte do autor de Lance de dados. A cerimônia perseguia, conceitualmente, a morte do autor, fazendo com que cada um dos participantes se parecesse por cinco minutos ao defunto Mallarmé. A função autor revelava-se, portanto,

4 “El silencio por Mallarmé", de Eugenio D’Ors, publicado na Revista de Occidente (1923, p. 244-246). Foi mais tarde recolhido em Cinco minutos de silencio (1925, p. 15-17) e, posteriormente, em Nuevo Glosario (1947, p. 740-741). 
vazia. Ganha assim outro sentido o julgamento de D’Ors, no sentido de que o Martín Fierro é um poema mais complexo do que a Hérodiade de Mallarmé.

Em resposta, precisamente, a uma enquete da Revista de Ocidente, a publicação de Ortega, dirigida aos participantes, D’Ors associa o funeral mallarmaico com a separação entre poesia e filosofia apontada mais adiante por Agamben, quem foi, lembre-se, discípulo de Bergamín. A propósito, a redação da Revista de Ocidente questiona-lhe em que cada um dos participantes pensou, nesses minutos de suspensão. D’Ors responde:

Espero que no se tache de cinismo mi declaración de que pensar, lo que se llama pensar, no pensé nada en la coyuntura. Yo sólo pienso cuando hablo o escribo, es decir, cuando articulo y redacto. Incapaz de encontrar el menor sentido a la antigua y desacreditada separación entre "fondo" y "forma", no he logrado jamás pensar sino con y por las palabras (u otras formas, como las líneas, puesto que con frecuencia dibujo también)... He conducido, además, algunos esfuerzos de teorización filosófica a fortificar mi sospecha de que a todo el mundo le ocurre lo mismo.

A falta de pensamientos, puedo traer aquí algunas larvas. Puedo referirme al resumen - esquematizado, naturalmente, con cierta arbitrariedad - en que ya quedó fijada, para una de mis glosas, referencia sucinta de cuáles fueron mis pálidos contenidos de conciencia, durante los píos cinco minutos dedicados a la conmemoración a Mallarmé. (D’ORS, 1925a, p. 15-16)

Mas os cinco minutos de silêncio revelam, entretanto, um secreto vínculo com a oikonomia, porque o próprio D’Ors é consciente de que a expressão "cinco minutos", usada para designar uma unidade, é equivalente ao francês sou, com o qual antecipa-se aos três vinténs com que Brecht e Weil analisariam, em 1928, as relações entre linguagem e poder:

He escrito más arriba "píos cinco minutos", y lo he escrito con alguna repugnancia. ¿Por qué no convendríamos un término singular y sintético, para designar los "cinco minutos" como unidad, al modo como el sou francés y nuestra perra chica designan, también como unidad, a los cinco céntimos? "Cinco minutos", "diez minutos" nos aparecen en nuestra vida práctica, muy frecuentemente, como entidades vivaces y dotadas de imperio, que están pidiendo a gritos un símbolo propio, con el mismo derecho, o más derecho, que el "cuarto de hora" - expresión que, por otra parte, tiene en su carácter analítico, la razón de cierta debilidad - ... El hijo de Darwin dice de su padre, en la biografía: "Una de las razones de la superioridad de Carlos Darwin para el trabajo era que sabía distinguir, con nitidez, diez minutos de un cuarto de hora." (D’ORS, 1925a, p. 16-17) 


\section{Tectonismo dinâmico}

Mas, por outro lado, esse distanciamento ou hiato imposto pela forma que se revolta contra a arquitetura formal do Estado, ganhava, paralelamente, plena cidadania nos escritos artísticos de Eugenio D’Ors, fortemente marcado plea historiografia alemã. Com efeito, sabemos que, já em 1917, Heinrich Wölflin discriminara a forma fechada da forma aberta e julgara esta última não apenas um relaxamento da primeira, como também uma nova maneira de representação que deveria sem mais ser aceita como legítima. Em seus Conceitos fundamentais de História da Arte (Kunstgeschichtliche Grundbegriffe), traduzido ao espanhol por José Moreno Villa, um dos silenciosos admiradores de Mallarmé, graças à mediação, aliás, de outro deles, Ortega y Gasset, em 1936, Wölfflin afirma, peremptório, que

Toda obra de arte es una estructura, un organismo. Lo que la distingue esencialmente es su carácter de forzosidad; es decir, que en ella ha de ser todo como es, sin que sea posible variar nada. Si en este sentido cualitativo, pues, cabe decir de un paisaje de Ruysdael tanto como de una composición de Rafael, que son algo absolutamente cerrado, existe, sin embargo, la diferencia de que en uno y en otro fué obtenido desde bases distintas aquel carácter de forzosidad; en el siglo XV italiano se luchó por alcanzar la perfección más alta en un estilo tectónico; durante el siglo XVII holandés fué el libre estilo atectónico la única y posible forma de representación para Ruysdael.

Sería deseable que existiese una palabra especial para distinguir inequívocamente la composición cerrada en sentido cualitativo de lo que es simple base de un estilo representativo conformado tectónicamente, como lo tuvimos en el siglo XVI y solemos oponer al atectónico del siglo XVII. A pesar de su sentido equívoco, adoptamos para el título los conceptos de forma cerrada y forma abierta, porque con su generalidad califican mejor el fenómeno que los de tectónico y atectónico, y además son más precisos que otros aproximadamente sinónimos, como, por ejemplo, riguroso y libre, regular e irregular y otros parecidos.

Por forma cerrada entendemos la representación que, con medios más o menos tectónicos, hace de la imagen un producto limitado en sí mismo, que en todas sus partes a sí mismo se refiere; y entendemos por estilo de forma abierta, al contrario, el que constantemente alude a lo externo a él mismo y tiende a la apariencia desprovista de límites, aunque, claro está, siempre lleve en sí una tácita limitación que hace 
posible precisamente el carácter de lo concluso en sentido estético. (WÖLFFLIN, 1945, p. 167-168)

A categoria de tectônico, presente também em Adolf Hildebrand (Das Problem der Form in der bildenden Kunst, 1893), em Wilhelm Worringer (Abstraktion und Einfühlung, 1921) e no livro de Alois Riegl sobre a indústria artística do Império Romano tardio segundo as descobertas no Império Austro-húngaro (Spätrömische Kunstindustrie, 1901-1923), acima citado por Hamacher, tudo isso fundamentaria certas análises de D’Ors, mas sofreria também uma forte reconfiguração nos escritos de Carl Einstein. Nos “Aforismos metodológicos”, publicados em sua revista Documents, que co-dirigia com Bataille, Einstein elabora uma teoria da exasperação do tectônico, em nome de uma função psicológica dinâmica, capaz de dar uma reviravolta nas concepções costumeiras de espaço e tempo:

Se consideraba el espacio como una base rígida de existencia narrada y como el símbolo mismo de continuidad. En este sentido, el arte servía a la representación de los muertos y la imagen debía garantizar su supervivencia. La representación de los muertos se llevaba a cabo de dos maneras diferentes. En primer lugar, como una representación naturalista que no se debe explicar - tal y como suele hacerse - por la alegría de vivir, sino por el miedo ante la muerte. Obsesionados por el miedo a la muerte, intentamos eternizar la existencia de nuestros antepasados y mantener la continuidad perpetua de la familia o de la tribu ya que, en este sentido, la familia no es sólo la alianza de los vivos, sino el conjunto de los vivos y los espíritus de los muertos. Por otro lado, el muerto se hace vivo en la imagen, y se eliminan las formas monstruosas de los malos espíritus, de manera que nos olvidamos de ellos. En cierto modo, un exorcismo. En segundo lugar, existe una especie de realismo metafísico en el arte exótico y arcaico. No se pretende representar al muerto mismo, sino su Ka o su alma de sombra y, de esta representación de las sustancias indestructibles, proviene un arte de lo estático y lo permanente. Tendríamos, de esta manera, una manera de explicar el carácter tectónico de tales obras de arte.

La obra de arte sacro es, por así decirlo, creada por lo invisible, provocada por la desaparición, la no existencia de un ser. La obra de arte es una protección contra lo invisible que campea y asusta por todas partes, una barrera al animismo extendido que amenaza con despedazar las creencias. El naturalismo del hombre religioso es una defensa contra las monstruosidades de la fantasía religiosa. Se disponen un canon y formas académicas contra el infinito y las analogías instantáneas de la imaginería religiosa. Este academicismo es el signo de los límites psicológicos y de la estrechez de un espíritu temeroso. (EINSTEIN, "Aforismos metódicos", p. 39-40)

A suspensão do ritmo corriqueiro serviria então, em poucas palavras, para a emergência do Real, isto é, a destruição do natural. Lembre-se 
que, mais adiante, analisando os quadros pintados por Picasso em 1928, Einstein acrescentaria que essa expansão de tempo e espaço não tem

Nada que ver con las imágenes metafóricas: no se trata ya de alegorías de la realidad. No cabe comprobación alguna: los elementos imaginarios no adaptados no se pueden comprobar. Hemos olvidado la convención de la realidad, que ha permanecido, por otro lado, objeto de una auténtica adoración, como si de una sustancia transcendental se tratara. Estamos situados fuera de lo normal, simple abstracción de las representaciones automatizadas que encontramos por todas partes "amañadas". Hemos desechado la monotonía biológica, insuficiente para las alucinaciones.

Picasso no acepta las cosas dadas, aún adoradas por los débiles como una sustancia trascendental. Con él salimos de la alucinación fatalista y estable de Freud, expresión limitada donde está representado el inconsciente, de una manera metafísica, como una sustancia constante. La estática de estos cuadros es el resultado de largos pero rápidos procesos. Es una compresión que libera reacciones tanto más fuertes cuanto más violenta sea. Los cuadros son encrucijadas de los procesos psicológicos dirigidos por el artista. Estas construcciones descansan sobre capas muy profundas, en el sentido de que no hay nada más humano ni más inconsciente que la geometría de las formas. Sin embargo, no cabe hablar, en el caso presente, de arcaísmo o de visión retrógrada y primitiva: estas formas, en apariencia simples, presentan orientaciones en el espacio susceptibles de diversas interpretaciones. Una línea geométrica está definida en un sentido para llegar a una solución: la fuerza de las líneas de Picasso proviene de la multiplicidad de ejes integrados, correspondiéndose cada forma, de una manera telepática, con todas las formas del cuadro. (EINSTEIN, "Pablo Picasso. Algunos cuadros de 1928”, p. 165-166)

\section{Para, mais adiante, concluir:}

Estos cuadros imaginativos muestran una estructura completamente inventada. Debido a una determinada geometría de las partes figuradas, se ha pretendido que una pintura semejante fuera racionalista, pero esta objeción es fácilmente refutable, ya que a las épocas míticas justamente les corresponde casi siempre un arte tectónico, sin que lo tectónico sea nunca un medio de reproducción. Aún podríamos decir que, a partir de 1908, la figura se ha vuelto funcional y que la hemos humanizado. Constatamos un tipo de animismo formal, por el hecho de que ahora la fuerza vivificante no procede de los espíritus, sino del hombre mismo. Ya no se trabaja según la imagen de los dioses, sino según sus propias nociones. Por este motivo, las formas tectónicas, no siendo mensurables, nos parecen más humanas, ya que son los signos de un hombre visualmente activo, que ordena él mismo su universo y se niega a ser esclavo de las formas dadas. (EINSTEIN, "Notas sobre el cubismo", p. 51)

Para Einstein, essa transformação das formas tectônicas da arte, introduzindo movimento a partir de uma suspensão das funções normais, 
era a contribuição do cubismo à arte moderna. Em sua história da arte no século XX, publicada em Berlim em 1931, Einstein afirma:

Les cubistes concrétisaient désormais en objets les représentations du mouvement lié au volume ; on utilise alors les facteurs structurants de l'espace pour créer des objets. L’acte de voir est activé au profit de celui qui regarde, l'objet étant dynamisé en symptôme de la vision. Commence un isolement du subjectif qui est ressenti comme fonction et davantage valorisé que les immédiat ; c'est pourquoi ces tableaux cubistes, malgré leur construction tectonique, comportent une dynamique significative. Grâce à pareil isolement du subjectif, on acquit une liberté considérable par rapport à l'environnement et aux choses. (EINSTEIN, 2011, p. 107-108)

Se interpretamos, então, a sextina de Hernández como composição, à maneira cubista, diríamos que, dinamizada, ela é um peculiar sintoma de declínio épico. Apesar de sua sólida construção tectônica, a estrofe do Martín Fierro teria o traço peculiar de rechaçar o espaço como base da existência narrada ou mesmo como símbolo de uma evolução contínua. A sextina não garante a manutenção do poder, nem a representação da morte, nem a passiva sobrevivência da tradição. Em Martín Fierro, como na Hérodiade, a morte torna-se viva na imagem, em nome de uma espécie de realismo metafísico, que D’Ors certamente associa com a poesia do romanceiro, onde se encontra também não só uma certa indecisão, mas uma consistente melancolía, Mas, mesmo não sendo o romance uma estrutura poética plenamente contemplativa; ele já é, na opinião de D 'Ors, um organismo poético indolente, característica que, no Martin Fierro, só faz crescer. Em um texto contemporâneo, "Glosa sobre a Bolívia” (1925), onde Bolívia-a terra dedicada ao homem novo, Bolívar-vale pela América Latina em seu conjunto, D’Ors explicita, de maneira luminosa, a indecidibilidade entre ativo e passivo:

La minoría selecta de los creadores intelectuales ejerce aquí, como en cualquier parte, una función - que puede incluso tener carácter de involuntaria- sobre la sociedad a que pertenece... Ya se entenderá, cuando hablo de creaciones espirituales, que no me refiero exclusivamente a la producción de libros. El artículo, el discurso, la conversación, la correspondencia y aun el hecho sencillo de adoptar, de mantener y cambiar ciertas costumbres elegantes, tiene también su precio para la pro-ducción de valores. Salte ahora nuestra observación desde esta minoría culturalmente activa al otro extremo: a la inmensa masa que ocupa, frente a aquélla, una posición de "pasividad". Cuando esta masa inmensa pertenece a una raza o razas primitivas, el problema de su civilización se complica bastante. Pero, en rigor - ya lo hemos dicho-, si pasando de uno a otro país el término "raza" se sustituye por el término "pueblo", aquel problema no varía demasiado. Y aunque "pasividad" no signifique, precisa y necesariamente, "resistencia”, siempre hay, en la 
existencia de esta mayoría pasiva, para el otro elemento, para la minoría culturalmente activa, una dificultad, una angustia tal vez.(...) Por un lado, la minoría de cultura, con su instrumento de enseñanza. Por otro lado, el pueblo primitivo, con su instrumento de folklore y especial-mente de arte popular. Dramática simetría: dos contra dos. (D’ORS, 1925b)

D'Ors compreende cabalmente que a questão da gauchesca (e da poesia latino-americana como um todo) passa por certa noção de Kulturkampf, como ele mesmo admite e como era, aliás, proposto por Gramsci naquela mesma época ${ }^{5}$, mas, euforicamente, julga que em poucos anos ela se resolveria. Muito depois, porém, em 1950, o panorama não mudara essencialmente, e mais uma vez tomando a Bolívia como referente, condena o rigor formalista de um poeta como Ricardo Jaimes Freyre, grande admirador de Cruz e Souza, em quem D'Ors intui um receio de confundirem o lirismo culto dele "com el sollozar lastimero de la quena del pastor" (D’ORS, 1950, p. 136). Se, na sociedade, há um intervalo não preenchido, um vácuo simbólico, e se a questão da linguagem passa pela emancipação desse intervalo, como pretendia Riegl, então D’Ors está nos dizendo, em poucas palavras, que a poesia latino-americana nasce da indolente contemplação da poesia canônica europeia.

Ora, não deixa de ser surpreendente que, mais ou menos na mesma época, final dos anos 20, analisando, porém, a pintura de Goya, Eugenio D’Ors elaborasse julgamentos muito em linha com o raciocínio de Carl Einstein, associando a pintura de Goya ao dinamismo, à ruína e, portanto, ao barroco que, a seu ver, era algo eminentemente oriental, isto é, trazido à península por Portugal. Nessa montagem anacrônica, sextilha, paisagem e ruína surgem justapostos enquanto sintomas do moderno porque "el esquema de la ruina, característico de los paisajes, en las mismas tierras donde mejor ha florecido el barroco, puede aplicarse al tectonismo de Goya”. E a seguir:

“OLLA PODRIDA”. - Sí, las obras de Goya son, tectónicamente, una ruina. Pero son una ruina sabrosa. El mismo fraccionamiento, la misma mescolanza, la misma incoherencia íntima de las intenciones, parece dar a cada elemento, a cada fragmento, a cada tropezón de materia pictórica, el máximo de su

${ }^{5}$ No XII dos Cadernos do cárcere, Gramsci analisa o impacto da crise do capitalismo, em 1930, a partir do conceito de Kulturkampf no México até a insurreição "militar popular" na Argentina, no Brasil, no Perú, no Chile e na Bolivia descrevendo-as como situações em que o elemento laico e burguês ainda não conseguiu subordinar aqueles interesses tradicionalistas, que sofrem a influência clerical e militar, à política laica do Estado moderno. 
intensidad, el máximo de su calidad voluptuosa. Y aquí, al considerar con simpatía, con los sentidos bien abiertos, el secreto de esa estructura, el término definitorio, se nos viene a la imaginación sin esfuerzo. Nos llega, (puesto que ya de sabores se trata, puesto que aquí el gusto se fabrica un goce en la misma interior contradicción sensorial) el recuerdo de estos guisotes de la cocina popular y castiza, donde también la multiplicidad es ley y la abigarrada contradicción de elementos, la multipolaridad de intenciones, la alternativa entre la fluidez y la consistencia, entre el grano minúsculo y el recio tropezón. El recuerdo de estas paellas, estos pucheros, estas "ollas podridas" de la mesa hispana, donde todo se junta y revuelve: lo cocido, lo crudo, lo semicrudo, la carne y el pescado, la vianda y la legumbre, el embutido y la verdura, lo seco y lo salsero, los huesos y los caldos, lo íntegro y lo trinchado, en divertida, y gruesa, y a la vez delicada suscitación salivera de la multiplicidad.

Es curioso imaginar cómo, en un laboratorio donde se aplicaran al estudio del hambre específica, según los métodos de Pawlow, estos platos nuestros, reaccionarían en la secreción de sus jugos anticipados, los sujetos sometidos a experimentación... Pero el experimento no tiene nada de hipotético. Advirtamos que la reacción gustativa en el caso imaginado, no sería otra cosa que la aplicación a dominio apenas distinto de las reacciones que en nuestra sensibilidad se producen con la contemplación de las obras goyescas. (D’ORS, 1928)

A reivindicação da olla podrida, nome dado ao que, em música, se conhece como variação, remonta, entre outras fontes, aos Vinte poemas para serem lidos no bonde (1922), de Oliverio Girondo, redator também do manifesto da revista Martín Fierro, em sua fase vanguardista, e coincide, temporalmente, com a posição antropofágica de Oswald de Andrade, o que ainda lança outras luzes sobre a leitura que os modernistas podiam estar fazendo do poema de Hernández. Em todo caso, para D’Ors, a leitura era sinestésica e seu efeito paradoxal, o que, en passant, situa a deriva pró-barroca do Oswald pós-1945:

También para la pintura hay una gula. También para los fragmentos de pintura hay una hambre específica. También aquí, interiores salivas, más o menos químicamente apreciables; nos preparan a atender qué es una manera de mascar, nos llevan a comprender qué es una manera de digerir.

Goya, puchero; Goya, paella; Goya, olla podrida, es un plato fuerte. Nuestra sensibilidad se ve en él a un tiempo atraída y castigada. Su deglución será accidentada siempre; su digestión, difícil. Pero siempre tendrá Goya un aire de fiesta, con el cual todo nuestro ser rimará las ideas de la exaltación y del alborozo. (D'ORS, 1928)

\section{A literatura latino-americana, uma ruína saborosa}

Deixou marcas, na crítica contemporânea, a leitura de D’Ors? Não ousaria afirmá-lo. Em perspectiva textualista, Noé Jitrik abordou, no 
centenário da obra, o problema do canto (1971, p. 23-46); mas, na esteira dessas observações, Beatriz Sarlo e María Teresa Gramuglio não deixaram de observar também certa fala distópica, no poema de Hernández:

\begin{abstract}
Martín Fierro está escrito en versos octosilábicos, metro que refuerza su vinculación con lo popular y con la gauchesca, pero predomina una forma estrófica, la sextina, cuya originalidad lo diferencia notablemente del resto de estas producciones. Más allá de las discusiones acerca de los modelos que subyacen bajo esta estrofa típicamente hernandiana, vale la pena destacar que su economía la hace sumamente eficaz para transmitir un contenido narrativo que se va puntuando con enunciados reflexivos y valorativos que se integran en la acción y al mismo tiempo pueden desprenderse de ella. Su esquema, más ceñido que los de la décima y el romance, menos puntual que el de la cuarteta, posibilita agrupamientos y trabazones reforzados por la rima y por las pausas sintácticas que configuran el modo especial de articulación del texto. Así, la tendencia a agruparse en dísticos, la relativa facilidad con que estos dísticos forman subunidades dentro de la estrofa, apuntan a cierto mimetismo del discurso con las formas del habla gauchesca tal como Hernández la veía, con su falta de enlaces lógicos, su desconocimiento de las reglas y otros rasgos que consigna en ambos prólogos, el de 1872 y el de 1879. (GRAMUGLIO; SARLO, 1981, vol. 2, p. 37)
\end{abstract}

É um horizonte de leitura bastante característico dos anos da redemocratização, quando a questão do Estado e sua reconstrução perpassava muitas análises, tais como as de Rama (1976; 1977, p. IXLXVI), preocupado com a noção de sistema, ou Ludmer, que propõe uma abordagem heteroglóssica, em que uma das grandes questões do poema é, precisamente, a da $\mathrm{Voz}^{6}$. São formas de se recriarem as leituras históricoalegóricas do período da guerra, quando boa parte das categorias com que a modernidade foi pensada, nos anos 20, passava por uma severa reescritura. O fenômeno teve ecos no Brasil. Assim, por exemplo, no final de 1946, Oswald de Andrade reescreve o manifesto de 1928:

O antropófago habitará a cidade de Marx. Terminados os dramas da préhistória. Socializados os meios de produção. Encontrada a síntese que procuramos desde Prometeu. Quando terminarem os últimos gritos de guerra anunciados pela era atômica. Porque "o homem transformando a natureza,

${ }^{6}$ El género gauchesco. Un tratado sobre la patria, tradução brasileira: O gênero gauchesco: um tratado sobre a pátria (2002). Algumas dessas hipóteses se radicalizam em O corpo do delito: um manual (2002) ou em "Temporalidades del presente" (2002, p. 1427), mais tarde incorporado a Aquí América latina. Una especulación (2010). Não apenas a muito citada pós-autonomia mas, fundamentalmente, o conceito de realidadficción de Ludmer são consequências, não necessariamente deliberadas, do tectonismo inconsciente de D'Ors e Einstein. (LUDMER, 2006, p. 26-31). 
transforma a sua própria natureza”. Marx. (ANDRADE, “Mensagem ao antropófago desconhecido da França antártica”, 1992, p. 286)

Em data incerta, porém próxima também do fim da guerra, Oswald redige um longo texto, "O antropófago", onde denuncia a existência de "uma grotesca caricatura de canção de gesta que é o poema Caramuru de Frei Santa Rita Durão”, uma absurda oitava real,

um gozado panegírico da legitimidade paterna, em que um guerreiro português conduz a noiva, a índia Paraguaçu, por um longo raid de caravela até terras da França, onde intata e virgem vai-se casar com o futuro criador de uma intocável genealogia colonial. (ANDRADE, “O antropófago”, 1992, p. 244)

Ora, para Oswald, pelo contrário, a saída pós-colonial era outra e não desdenharia o elemento órfico ("o sentimento órfico é uma dimensão do homem” (ANDRADE, “O antropófago”, 1992, p. 237)), uma vez que “o sentimento órfico é o subterrâneo alimento onde vicejam essas ardentes necessidades irracionais" (ANDRADE, "Do órfico e mais cogitações", 1992, p. 290) e a poesia "monumentaliza a linguagem fixando paixões, comandos, catástrofes, e paraísos de um modo imperecível. O poema é um monumento da língua que o produz" (ANDRADE, "Novas dimensões da poesia”, 1992, p. 119), nos diz Oswald com sotaque heideggeriano. Esses conceitos alinham-se, portanto, àquilo que Giorgio Agamben expõe, laconicamente, em $O$ reino e a glória:

L'isolamento innico della parola ha trovato nella poesia moderna il suo esito estremo in Mallarmé. Mallarmé ha durevolmente sigillato la poesia francese affidando un'intenzione genuinamente innica a un'inaudita esasperazione dell 'armonia austera. Questa disarticola e spezza a tal punto la struttura metrica del poema, che esso esplode letteralmente in una manciata di nomi slegati e disseminati sul fòglio. Isolate in una «vibratile sospensione» dal loro contesto sintattico, le parole, restituite al loro statuto di nomina sacra, si esibiscono ora, scrive Mallarmé, come «ce qui ne se dit pas du discours », come ciò che nella lingua tenacemente resiste al discorso del senso. Questa esplosione innica del poema è il Coup de dés. In questa irrecitabile dossologia, il poeta, con un gesto insieme iniziatico ed epilogante, ha costituito la lirica moderna come liturgia ateologica (o, piuttosto, teoalogica), rispetto alla quale l'intenzione celebrativa dell'elegia rilkiana appare decisamente in ritardo. (AGAMBEN, 2006, p. 261-262)

A liturgia é a exteriorização de um sentimento pelas cordas do social, dizia Oswald, pouco antes de morrer, no seu texto sobre o órfico. Agamben desenvolverá a hipótese de que a liturgia, originariamente, na Grécia, um serviço público, torna-se, no cristianismo, uma cisão do opus 
dei, que gera, assim, uma questão aporética, em que se reúne o mistério e o ministério, isto é, tanto o ato soteriológico eficiente, quanto o serviço comunitário dos clérigos, o opus operatum e o opus operantis Ecclesiae, o poder e o ofício, como suspensão temporária do poder (AGAMBEN, 2012, p. 38). E Hamacher nos relembrava a observação de Riegl no sentido de uma modificação decisiva na configuração do espaço na arte românica, que ele caracterizava como "emancipação do intervalo", cinco minutos de silêncio isolados de qualquer representação. Quando, também após 1945, o mesmo D’Ors retomasse a questão de América e a poesia, dirá, conclusivo:

En su esencia, el americanismo corresponde a una actitud ante la vida, de ruptura y originalidad respecto del pasado personal y familiar, respecto del pasado histórico. Cuando esta esencia se traduce a palabra política, trae acentos de áspera independencia; si a palabra social, comparecen los descamisados-y no es un vano capricho de propaganda partidista el santo y seña adoptado en algún lugar-, así como los deschaquetados de la comodidad deportiva; si a palabra poética - Aranguren lo dice-, a fundación, a comienzo; a creacionismo, a inmersión telúrica, que viene a dar un complemento a la liberación cultural. El indigenismo es sólo un aspecto de tal voluntario extravío en lo elemental y lo pánico. Paso adelante hacia una orfandad, el día en que, por milagro, todo ese cosmos sin ley se convirtiese en patricial, el americanismo puro tendría que volar («s'envoler») hacia el misterio de lo alado y de lo informe 7 . (D'ORS, 1954)

A leitura arquifilológica aquí proposta também emancipa o intervalo dos fenômenos ${ }^{8}$ e, indo além deles, descobre outros fenômenos, como o tectônico inconsciente, por exemplo, que emergem a partir do intervalo entre esses mesmos fenômenos, quer dizer, são movimentos fenomenais que se produzem graças a outros, afenomenais, num espaço intermediário, entre o Brasil e a América Hispànica, entre o oral e o escrito, entre o passado e o futuro, entre a autonomia e a acefalia, isto é, postulando uma quarta dimensão da cultura que se firma a partir do dado não-dimensional (HAMACHER, 2011, p. 18). Se a literatura latinoamericana é, portanto, uma ruína saborosa, é porque, em todo gesto de emergência do novo, tal como na estrofe gauchesca, predomina um gesto,

7 E conclui: "el Nuevo Mundo no significaba la tierra de la libertad, sino el logro del poder. Querían allí «ganar», no «perderse». No querían ser golondrina ni mariposa, sino propietarios en su pueblo y grandes cruces de Isabel la Católica... Y, ¿no ocurre que el mismo afán «centrípeto» sea el que, en Hispanoamérica, le ha salido al paso al proceso de descomposición del lenguaje, proliferando en provinciales puristas y en Academias filiales y limpiándose la boca de los lunfardos de la Boca?"

${ }^{8}$ Ver URBANI, 2012. 
ao mesmo tempo, principiante e epilogante, cinco minutos de silêncio, que traduzem uma liturgia ateológica, ou mesmo teoalógica9, uma construção exasperada, uma pulsação sem objeto, uma acquiescentia in se ipso, de caráter fortemente contestatário do opus como epos.

\section{REFERÊNCIAS BIBLIOGRÁFICAS}

AGAMBEN, Giorgio. Stanze: La parola e il fantasma nella cultura occidentale.Turim: Einaudi, 1977.

IDEM. Idea della prosa. Milão: Feltrinelli, 1985.

IDEM. L'aperto. L'uomo e l'animale. Torino: Bollati Boringhieri, 2002.

IDEM. Il regno e la gloria. Vicenza: Neri Pozza, 2006.

IDEM. La comunità che viene. Torino: Bollati Boringhieri, 2007.

IDEM. Opus Dei: archeologia dell'ufficio. Homo sacer, II, 5. Torino: Bollati Boringhieri, 2012.

ANDRADE, Oswald de. Estética e política. São Paulo: Globo.

ANTELO, Raul. Babel e a harmonia grotesca. In: PEDROSA, Célia; ALVES, Ida (orgs.). Subjetividades em devir: estudos de poesia moderna e contemporânea. Rio de Janeiro: 7Letras, 2008.

CHIAPPINI, Ligia. Martín Fierro e a cultura gaúcha do Brasil. In: HERNÁNDEZ, José. El gaucho Martín Fierro y La vuelta de Martín Fierro. París, Madrid: UNESCO, Colección Archivos, № 51, 2001.

D’ORS, Eugenio. El silencio por Mallarmé. Revista de Occidente. Año 1, vol. 2, ㄲo 5, nov. 1923.

IDEM. Cinco minutos de silencio. Valencia: Sempere, 1925.

IDEM. Glosas a la nación boliviana. La Nación. Buenos Aires, 6 ago. 1925.

IDEM. Tectónica goyesca. Notas concretas y precisas. Blanco y Negro, ABC. Madrid, a. 38, ํo 1926, 15 abr. 1928.

IDEM. Unas palabras de Xenius sobre el Martín Fierro. Libra. Buenos Aires, ํo. 1, inverno 1929, p.85-87.

IDEM. El silencio por Mallarmé. Nuevo Glosario. Madrid: Aguilar, vol. I, 1947.

IDEM. Letras de Bolívia. In: La palabra en la onda. Buenos Aires: Sudamericana, 1950.

IDEM. Vocación de América. El Norte de Castilla, 29 out. 1954.

EINSTEIN, Carl. El arte como revuelta. Escritos sobre las vanguardias (1912-1933). Trad. María Dolores Ábalos; Carmen Alcalde Aramburu. Madrid: Lampreave y Millán, s/d.

IDEM. L'art du XXe siècle. Trad. Liliane Meffre; Maryse Staiber. Arles: Jacqueline Chambon, 2011.

${ }^{9}$ A linha de fuga dessa Voz presente na gauchesca reitera-se, um século depois, na poesia de Leónidas Lamborghini. Tratei do assunto em "Babel e a harmonia grotesca" (2008, p.268-290). 
ESPOSITO, Catalina; PALOMARES, José. La 'Octava real' y la épica renacentista española. Notas para su estudio. Lemir, no 8, 2004.

GRAMUGLIO, María Teresa; SARLO, Beatriz. Martín Fierro. In: Historia de la Literatura Argentina. Buenos Aires: Centro Editor de América Latina, 1981.

HAMACHER, Werner. 95 tesis sobre la Filología. Trad. Laura S. Carugati. Madrid: Miño y Dávila, 2011.

HERNÁNDEZ, José. Los consejos del viejo Vizcacha y de Martín Fierro a sus hijos. Madrid, París, Buenos Aires: Agrupación de Amigos del Libro de Arte (A. L. A.), 1928.

JITRIK, Noé. El tema del canto en el Martín Fierro. In: El fuego de la especie. Madrid: Siglo XXI, 1971.

LUDMER, Josefina. El género gauchesco. Un tratado sobre la patria. Buenos Aires: Sudamericana, 1988.

IDEM. O corpo do delito: um manual. Belo Horizonte: UFMG, 2002

IDEM. O gênero gauchesco: um tratado sobre a pátria. Chapecó: Argos, 2002.

IDEM. Temporalidades del presente. Margens, márgenes. Belo Horizonte, no 2, dez. 2002.

IDEM. Algunas 'nuevas escrituras' borran fronteras. La biblioteca, Buenos Aires, 2006.

IDEM. Aquí América latina. Una especulación. Buenos Aires: Eterna Cadencia, 2010.

MATOS, Gregório de. Obras. II Lírica. Rio de Janeiro: Anuário do Brasil, 1923.

RAMA, Ángel. Los gauchipoliticos rioplatenses. Buenos Aires: Calicanto, 1976.

IDEM. El sistema literario de la poesía gauchesca. In: Poesía gauchesca. Caracas: Biblioteca Ayacucho, 1977.

SALDAÑA, José Maria Fernández. José Hernández emigrado en Brasil. La Prensa, Buenos Aires, 6 out. 1940.

URBANI, Giovanni. Per uma archeologia del presente. Scritti sull'arte contemporanea. Milano: Skira, 2012.

WÖLFFLIN, Enrique. Conceptos fundamentales de la historia del arte. Madrid: EspasaCalpe, 1945 . 